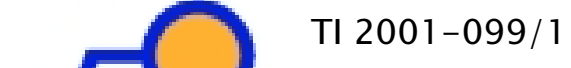 \\ Tinbergen Institute Discussion Paper \\ Customer Directed Advertising and Product Quality
}

Lola Esteban ${ }^{1,2}$

José M. Hernándezi,2

José Luis Moraga-González3,2

' Departamento de Análisis Económico, Facultad de Económicas, Universidad de Zaragoza,

2 Tinbergen Institute, ${ }^{3}$ Department of General Economics, Faculty of Economics, Erasmus University Rotterdam 
Tinbergen Institute

The Tinbergen Institute is the institute for economic research of the Erasmus Universiteit Rotterdam, Universiteit van Amsterdam and

Vrije Universiteit Amsterdam.

Tinbergen I nstitute Amsterdam

Keizersgracht 482

1017 EG Amsterdam

The Netherlands

Tel.: +31.(0)20.5513500

Fax: $\quad+31 .(0) 20.5513555$

Tinbergen Institute Rotterdam

Burg. Oudlaan 50

3062 PA Rotterdam

The Netherlands

Tel.: $\quad+31 .(0) 10.4088900$

Fax: $\quad+31 .(0) 10.4089031$

Most TI discussion papers can be downloaded at

http://www.tinbergen.nl 


\title{
Customer Directed Advertising AND PRoduct Quality
}

\author{
Lola Esteban, José M. Hernández and José Luis Moraga-González*
}

October 2001

\begin{abstract}
We consider a market where a single seller must employ informative advertising to launch a new product of observable quality. The monopolist may use mass, targeted or customer directed advertising. We show that the choice of advertising strategy depends on the economic properties of the advertising technology. If this exhibits strong economies of targeting, customer directed advertising arises in equilibrium. Mass and targeted advertising arise under conditions that seem empirically quite restrictive. We also show that different advertising strategies have a bearing on the market outcome. While under mass and targeted advertising the price-quality choice of the monopolist equals that under full information, under customer directed advertising the seller brings fewer units to the market, and distorts the quality of the product and the price in a direction that depends on the nature of product quality.
\end{abstract}

Keywords: customer directed advertising, mass advertising, monopoly, quality, targeted advertising

JEL Classification: L12; L15; M37

\footnotetext{
${ }^{*}$ We thank Francisco J. Casado-Izaga, Sanjeev Goyal, Bauke Visser and the participants at the XVII Jornadas de Economía Industrial (Barcelona, 2001) for their comments. This paper began when the first two authors were visiting Tinbergen Institute Rotterdam, whose hospitality is gratefully acknowledged. Esteban and Hernández acknowledge financial support from the Spanish Ministry of Education, through DGES grant PB98-1602, and Moraga-González from the EU through the TMR post-doctoral grant No. ERB4001GT973264.

Addresses for correspondence: Esteban and Hernández: Departamento de Análisis Económico, Facultad de Económicas, Gran Vía 2, 50.005 Zaragoza, Spain, Phone: ++34 976 761823, Fax: ++34 976761996 , E-mails: lesteban@posta.unizar.es, hernande@posta.unizar.es.

Moraga-González: Erasmus University Rotterdam, Department of Economics H 7-17, Burg. Oudlaan 50, PO Box 1738, 3000 DR Rotterdam, The Netherlands, Phone: ++31 10 4088905, Fax: ++31 10 4089149, E-mail: moraga@few.eur.nl.
} 


\section{Introduction}

With the advent of the information era, advertising technologies have changed a great deal. While in the recent past firms launching new products could only reach their potential consumers by inserting advertisements in the mass media, nowadays sellers have at their disposal a vast amount of distinct advertising means, such as an array of cable and satellite radio stations and televisions, specialized magazines and newspapers, classified Internet homepages, etc. For instance, just in US, currently there are about 9,000 radio stations, 1,000 TV channels, 11,000 magazines, and 17,000 newspapers (Kotler and Armstrong, 1998). These different advertising media are characterized by distinct audiences, advertising rates and advertising efficiency. As a result, sellers of new products spend a great deal of effort to carefully select those advertising means that enable them to accurately target high valuation consumers, thus extracting the greatest value from any dollar spent on product development and advertising. This leads to the question of how various advertising strategies influence the pricing and the design of new products.

We study this influence in a market where a single seller offers a product of observable quality. Consumers are, in principle, unaware of the existence and the characteristics of the product and the monopolist uses informative advertising to promote sales. ${ }^{1}$ The advertising technology at the disposal of the seller allows for the distribution of advertisements to a specific target audience. In particular, the use of specialized advertising means enables the firm to focus its advertising effort on the most eager consumers. The paper addresses three central questions. The first issue pertains to the optimal selection of advertising strategy. Here, we distinguish three different advertising strategies and give theoretical conditions under which they arise in equilibrium. In addition, we discuss the empirical relevance of such conditions. The second issue has to do with the relationship between the advertising strategy and the equilibrium price-quality choice of the seller. Here, we find that different advertising strategies have a bearing on the market outcome. Finally, we ask what are the implications of the different advertising strategies on market performance from a social welfare point of view. Here, we find that these implications are sensitive to the nature of product quality. We elaborate on these results in what follows.

Our first concern is the equilibrium selection of advertising strategy. In this connection, we note that our advertising technology allows for three different advertising strategies: (i) mass advertising, (ii) targeted advertising, and (iii) customer directed advertising. We say that mass advertising arises in equilibrium when the seller chooses to place ads in the general media, i.e., when advertisements are not targeted to any particular segment of consumers. We refer to targeted

\footnotetext{
${ }^{1}$ The model is consistent with the launching of a new product; in such a case, a new market is created and thus it seems reasonable to assume that a firm holds substantial market power.
} 
advertising as the case in which the monopolist segments the market by distributing ads to some segment of the population who values the good more, leaving the rest of the potential consumers who value the good less ignorant. We pay special attention to a situation in which the seller targets ads only to some set of consumers who are willing to buy the advertised price and quality combination. We call this type of advertising strategy customer directed advertising to capture the fact that the seller distributes no advertisements to those consumers who are rationed by the pricequality mechanism. In addition to the nature of the target audience of these different advertising strategies, they involve the placing of ads in distinct advertising means, which, in turn, entails distinct costs and advertising effectiveness.

We find that the relative attractiveness of these advertising strategies hinges upon the interplay between advertising cost and advertising efficiency. This relationship is nicely captured by two properties of an advertising technology. We say that an advertising technology exhibits economies (diseconomies) of targeting if, for a given number of ad inserts, the advertising cost per consumer reached diminishes (raises) as one moves from less to more specialized advertising means. A stronger property of an advertising technology which has a substantial bite in our model is that of strong economies (diseconomies) of targeting. These arise when the advertising cost decreases (increases), while consumer audience increases (decreases) as we move advertisements from less to more specialized means. We show that when the advertising technology presents strong economies of targeting, customer directed advertising arises in equilibrium. By contrast, the existence of strong diseconomies of targeting does not suffice to observe mass advertising in equilibrium. From a theoretical point of view, this suggests that mass advertising as an informative strategy can be regarded as a rather exceptional phenomenon. After all, whether advertising technologies exhibit (some degree of) economies or diseconomies of targeting is a matter of empirical verification. In this connection, we provide some evidence based on Dutch and Spanish Press and Publicity Handbooks to support the view that current real-world advertising technologies do not present strong diseconomies of targeting and, further, that the conditions under which customer directed advertising arises in equilibrium seem to hold.

Our second set of results pertains to the relationship between different advertising strategies and the market outcome. We find that the price-quality choice of the monopolist under mass advertising as well as under targeted advertising equals the price-quality choice under full information. Thus, apart from the different advertising intensities that arise in equilibrium, these distinct advertising strategies have no influence on the market outcome. By contrast, under a customer directed advertising strategy, the seller brings fewer units to the market, and distorts the quality and the price in a manner that hinges upon the nature of product quality. 
We distinguish amongst two settings regarding the nature of product quality. The first refers to a situation in which the willingness to pay for an extra unit of quality is higher for those consumers who have higher valuations for the good. In such a case we say that quality is an 'intrinsic' attribute to the product. Technical superiority features are examples in which quality has this nature, like operation speed of microprocessors in the market for computers. We show that when quality is an intrinsic attribute to the product, then a customer directed advertising strategy is accompanied by quality upgrading. As a result, customer directed advertising results in lower quantity, higher quality and higher price when quality is an intrinsic attribute to the product. The second setting we consider is one in which the willingness to pay for an extra unit of quality is lower for those consumers with higher valuations for the good. We say in this case that quality is an 'extrinsic' attribute to the product. Also in the market for computers, provision of side services like operating system tutorials, or home installation is an example in which quality has this nature. We show that when quality is 'extrinsic' the monopolist downgrades the quality of the product and the price implication is ambiguous.

We finally focus our attention on some welfare aspects related to the use of different advertising strategies. We first show that the private and the social incentives to use a customer directed advertising strategy are somewhat aligned. Indeed, if the advertising technology presents strong economies of targeting, a social planner employs customer directed advertising to promote sales, which is consistent with the seller's choice. However, the private and the social incentives for quantity and quality provision are generally misaligned. In this connection, we note that, compared to a full information setting, the social planner always reduces both quantity and quality when he promotes sales through customer directed advertising. This is inconsistent with the seller's decision since he upgrades quality in some cases. This misalignment of incentives leads us to ask what are the implications that the availability of advertising technologies presenting strong economies of targeting has on social welfare. The answer to this question requires to trade off the gains and costs brought about by the use of a customer directed advertising strategy. On the one hand, customer directed advertising entails a higher advertising cost efficiency than mass advertising; on the other hand, the former may lead to a greater dead-weight loss than the latter. Our results suggest, first, that overall welfare gains typically arise from the private use of customer directed advertising rather than mass advertising; second, that these gains are mostly captured by the seller; finally, that if there is a case for which customer directed advertising reduces welfare, this case is weakened when quality is an 'intrinsic' attribute to the product.

Our model is related to the economics literature on informative advertising. ${ }^{2}$ This literature has

\footnotetext{
${ }^{2}$ There is another branch of the economics literature dealing with persuasive advertising (see e.g. Bloch and
} 
distinguished between advertising that is directly informative, i.e., that conveys 'hard' information (see e.g. Bester, 1995; Bester and Petrakis, 1995; Butters, 1977; Caminal, 1996; Grossman and Shapiro, 1984; Moraga-González, 2000; Robert and Stahl, 1993; Shapiro, 1980; Stahl, 1994; and Stegeman, 1991), and advertising that is indirectly informative, i.e., that functions either as a signal of private information (see e.g. Bagwell, 1988; Bagwell and Ramey, 1990; Kihlstrom and Riordan, 1984; and Milgrom and Roberts, 1986) or else as a market coordination mechanism (see Bagwell and Ramey, 1994a, 1994b). Our paper deals with informative advertising that is directly informative and thus relates to the first strand of this literature. Those papers, however, differ from ours in that they do not consider the existence of specialized advertising means that allow sellers to target advertisements to particular segments of the potential market. In this connection, it is interesting to see the profound implications that targeting possibilities may have on product quality and price in a monopoly setting. There is also a related number of papers which have studied strategic coupon targeting in various segmented markets (see e.g. Bester and Petrakis, 1996; and Moraga-González and Petrakis, 1999). In a way, these articles assume the existence of an array of advertising means that enable sellers to target discount coupons to the most price sensitive consumers. More closely related to our work are Hernández (1997), and Esteban, Gil and Hernández (2001), who also assume that a seller can target ads to high valuation consumers. These papers have compared the equilibrium price of a monopolist under mass advertising and under targeted advertising for a particular advertising technology in the spirit of that of Grossman and Shapiro (1984). The present paper, by contrast, studies the flow of influence between product quality and advertising strategy under fairly general advertising technologies.

The remainder of the paper is organized as follows. Section 2 describes the model. The distinct equilibria of our model are characterized in Section 3. Section 4 is devoted to the welfare implications of customer directed advertising. Section 5 closes the paper with a review of the main conclusions.

\section{The model}

Consider a single producer trying to sell a new good of quality $s$ at price $p$ in an imperfect information setting. Let $Q(p, s)$ be the demand function under perfect information and $P(q, s)$ the inverse demand function. As usual, assume that demand is twice differentiable, downward slopping, i.e., $P_{q}^{\prime}(q, s)<0$, and that quality is desirable, i.e., $P(q, 0)=0$ and $P_{s}^{\prime}(q, s)>0$. Let $c(s)$ denote the marginal cost of producing one unit of a good of quality $s$. We assume that production of higher Manceau, 1999; Dixit and Norman, 1978; and Kaldor, 1950). 
qualities is more costly, i.e., $c(0)=0$ and $c^{\prime}(s)>0 .^{3}$

Consumers a priori ignore the existence, the quality and the price of the good. This implies that a potential consumer cannot be an actual buyer unless the seller invests in advertising and such a consumer is reached by the advertising campaign (Stahl, 1994). To specify the details of the advertising technology, it is useful to think of the demand function $Q(p, s)$ as stemming from a unitary mass of potential consumers represented by the unit interval [0,1]; these customers buy at most a single unit of the good. Each consumer in the unit interval has a willingness to pay $x(s)$ for a product whose quality is $s$, with $x^{\prime}(s)>0$. Assume that, for a given quality $s$, consumers can be ordered according to the valuations they place on the good and that such valuations decrease as $x$ increases. Under this convention, we note that the monopolist would ideally like to target advertisements to the consumers located somewhere towards the left part of the unit interval, because these are the customers who are willing to pay more for the good (Bagwell, 2001, p. 4).

\section{A general advertising technology:}

The distinctive feature of our advertising technology is that it allows the seller to choose the target of the advertising campaign. In particular, we assume that for any $t$ in the unit interval $[0,1]$, there is at least one advertising means that disperses ads to the consumers in $[0, t]$. We will refer to $t$ as the target of the advertising campaign. Given a price-quality pair $(p, s)$ such that $1>Q(p, s)>0$, we shall distinguish among three different advertising strategies. (i) A target $t=1$ picks up the case of mass advertising, i.e., advertising that is directed to the entire population of potential consumers, rather than being directed to a particular consumer segment. (ii) A target $t$ such that $1>t>Q(p, s)$ refers to the case of targeted advertising, where the firm uses specialized media to send messages towards consumers who value its product most. (iii) The case $t \leq Q(p, s)$ turns out to be of primary interest since ads are only distributed to the consumers who are not rationed by the price-quality mechanism, i.e., to those consumers who are willing to buy quality $s$ at price $p$. We refer to this case as customer directed advertising, since every ad returns a sale. ${ }^{4}$

An advertising technology is described by a pair $\{A(n, t), r(n, t)\}$. The first element of the advertising technology is the cost of the advertising campaign. We denote by $A(n, t)$ the cost of

\footnotetext{
${ }^{3}$ We also assume that $P_{q q}^{\prime \prime}<0, P_{s s}^{\prime \prime}<0, c^{\prime \prime}(s)>0$, which are necessary for the second order conditions to be fulfilled.

${ }^{4}$ We note first that the modeling of targeting adopted here is consistent with frequently encountered structures of specialized advertising media in which the degree of media specialization is positively correlated with consumers' valuation of the good. Accordingly, in many real-world situations the use of targeted advertising enables the seller to concentrate ads on the most eager consumers. Second, the specification adopted here rules out the possibility of sending different messages to disjunct sets of buyers. If this was possible, the seller's opportunities to segment the market would be unlimited, and, consequently, he would be able to practice third-degree (or even first-degree) price discrimination.
} 
placing $n$ ads of target $t$. For a given target $t$, we assume that $A_{n}^{\prime}(n, t)>0$, i.e., advertising costs increase with the number of ads acquired. The second element of the advertising technology is the probability $r(n, t) \in[0,1]$ with which each consumer becomes informed about the existence, quality and price of the good, when the seller acquires $n$ ads of target $t$. In other words, $r(\cdot)$ is the chance that a targeted consumer sees at least one advertisement. We assume that, given a target $t$, this probability increases with the number of ads $n$ placed by the seller, i.e., $r_{n}^{\prime}(n, t)>0$.

So far we have not imposed any structure on how advertising costs $A(\cdot)$ and advertising effectiveness $r(\cdot)$ relate to the target $t$. We shall distinguish among advertising technologies based on the following properties.

Definition 1: We say that an advertising technology $\{A(n, t), r(n, t)\}$ exhibits "economies of targeting" whenever, for any given number of advertisements $n$, it holds that

$$
\frac{d}{d t}\left(\frac{A(n, t)}{\operatorname{tr}(n, t)}\right)>0 .
$$

In words, an advertising technology exhibits economies of targeting when the advertising cost per informed consumer falls as the target $t$ decreases. If the opposite holds, we shall say that the advertising technology presents "diseconomies of targeting". Building on Definition 1, we now present a stronger property of an advertising technology. This property enables us to derive clearcut results regarding the seller's choice of advertising strategy.

Definition 2: We say that an advertising technology $\{A(n, t), r(n, t)\}$ presents "strong economies of targeting" whenever, for any given number of advertisements $n$, (i) $A_{t}^{\prime}(n, t)>0$, and (ii) $r(n, t)+$ $\operatorname{tr}_{t}^{\prime}(n, t)<0$.

In words, an advertising technology exhibits strong economies of targeting when, for a given $n$, advertising cost decreases and consumer awareness increases, as the target $t$ decreases. If the conditions (i) and (ii) hold with the opposite sign, we shall say that the advertising technology presents "strong diseconomies of targeting." We observe that an advertising technology which exhibits strong economies of targeting also presents economies of targeting. This can be seen by noting that $\{A(n, t), r(n, t)\}$ exhibits economies of targeting if and only if $A_{t}^{\prime}(n, t) \operatorname{tr}(n, t)-$ $A(n, t)\left[r(n, t)+t r_{t}^{\prime}(n, t)\right]>0$, which holds when the conditions (i) and (ii) in Definition 2 are satisfied. Observe, however, that the reverse implication does not hold.

We conclude this Section by relating our advertising technology $\{A(n, t), r(n, t)\}$ to a number of specific advertising technologies that have appeared in the economics literature on advertising. This literature has typically modelled advertising via a cost of message production. Imposing a particular structure on $A(n, t)$ and $r(n, t)$, our general advertising technology can encompass these 
advertising cost functions. As a result, each of these examples can be seen as a particular case of $\{A(\cdot), r(\cdot)\}$. We note that most of the literature has analyzed the case of mass advertising, i.e., $t=1$. Recent research by Hernández (1997) and Esteban et al. (2001) allows for advertising that can be targeted to the buyers with higher valuations.

\section{Examples:}

(i) Grossman and Shapiro (1984, p. 65) present an advertising cost function that generalizes the specification in Butters (1977). In their paper a seller has no ability to target advertisements to particular segments of the potential market. Therefore $t=1$. The per firm expenditure needed to reach a proportion $\phi$ of the consumers is $A(\phi)$, with $A_{\phi}^{\prime}>0$. To establish a connection between this advertising technology and $\{A(n, t), r(n, t)\}$, we note that in our model $r(\cdot)$ is monotone in $n$. As a result we can obtain the number of advertisements to be placed in the mass media so that a consumer sees an ad with probability $r$, i.e., $n=r^{-1}(r, 1)$. Substituting $n$ in $A(\cdot)$ yields $A\left(r^{-1}(r, 1), 1\right)=A(r)$. Setting $r=\phi$, the equivalence follows. An advertising cost function a la Grossman and Shapiro has also been used in, for example, Caminal (1996), Moraga-González and Petrakis (1999), Robert and Stahl (1993) and Stahl (1995).

(ii) A number of these papers have used specific functional forms to derive explicit solutions. A commonly used family of advertising cost functions is the polynomial: $A(\phi)=k \phi^{\beta}$, with $\beta>1$. We note that under this specification the advertising cost function presents constant-elasticity. Our advertising technology $\{A(n, t), r(n, t)\}$ accommodates this family of advertising cost functions by imposing the following structure on $A(\cdot)$ and $r(\cdot)$. Consider that the cost per ad of target $t$ is $a(t)$, and that the cost of sending $n$ ads of target $t$ is linear, i.e., $A(n, t)=n a(t)$. Then, setting $r(n, t)=n^{\alpha} f(t)$ we obtain

$$
A\left(r^{-1}(r, t), t\right)=a(t)\left(\frac{r}{f(t)}\right)^{\frac{1}{\alpha}} .
$$

Setting $a(1)=k, \beta=1 / \alpha$ and $r / f(1)=\phi$, the equivalence follows.

(iii) Specialized magazines with nested readerships (Esteban et al., 2001). This distribution of media ${ }^{5}$ assumes that for any $t \in[0,1]$ there is a large number of specialized magazines with readerships on the support $[0, t]$, in such a way that a seller can target high-valuation consumers

\footnotetext{
${ }^{5}$ Specialized magazines have often nested readerships. For instance, there are magazines containing general information on sports, medicine, computers, family matters, etc., as compared to those specialized in particular sports (soccer, basketball, golf, etc.), medical specialities (surgery, radiology, dermatology, etc.), computer issues (videogames, Internet, etc.) or leisure activities (fitness, decoration, gardening, etc.). We provide details of these structures for the case of medicine and computer magazines in Tables A.1 and A.2 in the Appendix.
} 
by carefully selecting a set of these magazines. In this context, the per firm expenditure needed to target a proportion $\phi$ of the consumers whose valuations lie in the set $[0, t]$ is $A(\phi, t)=n(\phi, t) a(t)$, with

$$
n(\phi, t)=\frac{\log (1-\phi)}{\log \left(1-\frac{z(t)}{t}\right)},
$$

where $z(t)$ is the readership of a magazine with target $t$. Our advertising technology accommodates a distribution of magazines with nested readerships assuming that $A(n, t)=n a(t)$ and $r(n, t)=$ $1-\left(1-\frac{z(t)}{t}\right)^{n}$. Setting $\phi=r$, the equivalence follows. ${ }^{6}$

\section{Analysis}

The monopolist's problem consists of choosing a tuple $\{p, s, t, n\}$ so as to maximize profits. Our primary concerns in this Section are two: first, we ask whether and under which conditions the different advertising strategies (mass, targeted and customer directed advertising) arise in equilibrium. Second, we analyze whether different advertising strategies have a bearing on the optimal price-quality choice of the firm and its market power. A welfare analysis is pursued in Section 4.

For future reference, let us denote $\left(p^{m}, s^{m}\right)$ as the equilibrium price-quality pair under fullinformation, i.e., $\left(p^{m}, s^{m}\right)=\arg \max \{\pi(p, s)=(p-c(s)) Q(p, s)\}$. Moreover, let $q^{m}=Q\left(p^{m}, s^{m}\right)$ and $\pi^{m}=\pi\left(p^{m}, s^{m}\right)$.

The optimal target of the advertising campaign, i.e., the nature of the advertising strategy, will depend on the properties of the advertising technology $\{A(n, t), r(n, t)\}$. Our first result states the conditions under which mass advertising is to be observed in equilibrium. We also note that when mass advertising arises in equilibrium, the price-quality choice of the monopolist is equal to that under full information.

Proposition 1 [Mass advertising]

If $A_{t}^{\prime}(n, t)<0$ and $r_{t}^{\prime}(n, t)>0$, the monopolist employs mass advertising to promote sales. Moreover, the seller's price-quality choice under mass advertising is equal to $\left(p^{m}, s^{m}\right)$.

\footnotetext{
${ }^{6}$ In fact, our advertising technology can be interpreted more broadly. For example, we can consider a nested distribution of magazines with only one magazine available for each target $t$. In this alternative framework, $n$ should be interpreted as the advertising effort exerted in a single magazine - e.g. the number of ads inserted in the magazine, the size and color of the ad, etc.-. Finally, our model accommodates other types of specialized advertising media such as cable television or radio. These media might not be nested, in such a way that the ads could be distributed in any interval in the set $[0, t]$.
} 
Proof. For any $p, s$, the profits of the monopolist are given by

$$
\Pi(\cdot)=(p-c(s)) \min \{Q(p, s), t\} r(n, t)-A(n, t)
$$

Assume, for the moment, that $\min \{Q(p, s), t\}=Q(p, s)$. We note that the price-quality pair that maximizes $(p-c(s)) Q(p, s)$ also maximizes $(p-c(s)) Q(p, s) r(n, t)-A(n, t)$. Therefore, $p=p^{m}$ and $s=s^{m}$. Differentiating (1) with respect to $t$ yields

$$
\Pi_{t}^{\prime}(\cdot)=\pi^{m} r_{t}^{\prime}(n, t)-A_{t}^{\prime}(n, t)
$$

Mass advertising arises in equilibrium if and only if the sign of (2) is positive, which holds when the conditions above are met. But $t=1$ is indeed greater than $Q\left(p^{m}, s^{m}\right)$, which completes the proof.

We now elaborate on some aspects of this result. We note first that the price-quality choice of the monopolist under mass advertising maximizes the full information profit. The reason is that under this advertising strategy, there does not exist a direct connection between the size of the potential demand and the advertising effort. Indeed, a marginal change in advertising intensity does not affect the difference between marginal revenue and marginal cost. As a result, neither the equilibrium price nor the quality level depends on the advertising effort.

Second, we note that the conditions sufficing for mass advertising to arise in equilibrium are intimately related to the nature of the advertising technology. In particular, the condition $A_{t}^{\prime}(n, t)<$ 0 holds if there are strong diseconomies of targeting. By contrast, the condition $r_{t}^{\prime}(n, t)>0$ is stronger than -and by implication not necessarily implied by- strong diseconomies of targeting. Inspection of equation (2) reveals that the presence of diseconomies of targeting, or even the existence of strong diseconomies of targeting, does not suffice for mass advertising to arise in equilibrium. We view this theoretical result as suggesting that the use of mass advertising to promote sales may be a rather exceptional phenomenon.

This theoretical observation is reinforced by existing empirical evidence suggesting that advertising technologies do not typically present strong diseconomies of targeting. For the case of cable television, Heighton and Cunningham (1984, p. 87) claim that the cost of an advertisement is usually inversely related, while the cost per consumer reached is directly related, to the degree of specialization of the channel employed. Accordingly, it seems reasonable to assume that $A_{t}^{\prime}(n, t)>0$, and, by implication, that advertising in cable television does not exhibit strong diseconomies of targeting.

We now report further evidence gathered by us supporting the same view, i.e., that $A_{t}^{\prime}(n, t)>0$. This evidence corresponds to a particular advertising technology for which we have found the 
necessary data, namely, that of specialized magazines with nested readerships described above. The information contained in Tables A.1 and A.2 given in the Appendix has been compiled from the 'Handbook of the Dutch Press and Publicity (2001)' (Handboek van de Nederlandse Pers en Publiciteit, 2001). ${ }^{7}$ This Handbook provides readerships and advertising rates for a very large set of magazines; these magazines are classified according to the field, subject or topic they treat. The different contents of various magazines can be seen as distinct degrees of specialization; we note that this is precisely the manner in which the Handbook interprets them.

To illustrate, we next discuss in some detail the case of medicine magazines (Table A.1). These are magazines generally read by the health care community. In line with the Handbook, in Table A.1, we have grouped some of these magazines in distinct categories, which correspond to the professional field in which (most of) the articles appearing in these magazines belong. It can be seen that there are general medicine magazines, and magazines specialized in Buccal Health, Cardiology, Logopedia and Phonetics, Midwifery, Neurology, Oncology, and Psychiatry. The table reports the readerships and the prices (in Euros) charged for a colored full page advertisement. We note that moving from placing ads in general medicine magazines, like Medisch Vandaag, to advertising in more specialized ones, for instance Tidschrift voor Verloskundigen specialized in midwifery, or Tijdschrift voor Kanker specialized in oncology, is interpreted in our context as concentrating the ads on a particular segment of the market (a decrease in $t$ ). Thus, if, for example, a pharmaceutical firm has developed a new drug intended to treat cancer, this firm can place ads in general medicine magazines, or in magazines specialized in oncology.

We have carried out the same examination for other markets, like the market for computers and computer software, or the market for leisure activities. In the market for computers, for instance, inspection of the Handbook reveals that there are general computer magazines and magazines specialized in Atari computers, Macintosh computers, the Nintendo 64 console, the Wordperfect word processor, the Internet, etc. (see Table A.2).

Using the information provided in Tables A.1 and A.2, we can analyze the sign of $A_{t}^{\prime}(n, t)$. For this purpose, we notice that, for the advertising technology under consideration, $A_{t}^{\prime}(n, t)=n a^{\prime}(t)$ (see above) and readily compute $a^{\prime}(t) \simeq \Delta a / \Delta t$, where $a(t)$ is approximated by the average cost per ad of the set of magazines with target $t$. As a proxy for $t$ to be used in the computations, we have chosen the largest readership of those magazines with the same degree of specialization. Table 1 provides these results.

\footnotetext{
${ }^{7}$ We also analyzed the data reported in the 'Spanish Guide to the Communication Media' (1999) (Guía de los Medios de Comunicación de España, 1999), which yielded a similar insight.
} 


\begin{tabular}{||l|r|r|r||}
\hline \hline \multicolumn{1}{|c|}{ Magazines } & Av. Ad price $a(t)$ & Target $t$ & $\mathbf{a}^{\prime}(\mathbf{t})$ \\
\hline \hline General Medicine & $3,100.75$ & 21,240 & \\
\hline \hline Cardiology & 2,599 & 2,500 & 0.0267 \\
\hline Neurology & $1,992.3$ & 1,875 & 0.0572 \\
\hline Buccal Health & 2,217 & 1,850 & 0.0455 \\
\hline Logopedia/Phonetics & 1,840 & 4,903 & 0.0770 \\
\hline Midwifery & 440 & 2,600 & 0.1427 \\
\hline Oncology & $2,301.5$ & 3,355 & 0.0446 \\
\hline Psychiatry & $2,225.75$ & 3,800 & 0.0501 \\
\hline \hline General Computers & $8,103.75$ & 187,499 & \\
\hline \hline Macintosh & 3,600 & 21,000 & 0.0270 \\
\hline Atari & 2,500 & 20,000 & 0.0334 \\
\hline Games & $6,370.4$ & 74,772 & 0.0153 \\
\hline Microsoft & 5,445 & 40,000 & 0.0180 \\
\hline WordPerfect/Corel & 4,300 & 25,000 & 0.0234 \\
\hline Windows & 5,350 & 40,000 & 0.0186 \\
\hline Nintendo64 & 4,250 & 18,000 & 0.0227 \\
\hline \hline
\end{tabular}

Table 1. Empirical Evidence on Dutch Magazines: $A_{t}^{\prime}(n, t)$

The empirical evidence reported in Table 1 suggests that moving an advertising campaign from less to more specialized magazines yields a cost saving, i.e., $A_{t}^{\prime}(n, t)>0$. On the basis of this observation, we conclude that real-world advertising technologies do not typically present strong diseconomies of targeting.

In what follows, we will investigate the conditions under which advertising strategies other than mass advertising arise in equilibrium. Moreover, we shall provide an account of the implications that these different advertising strategies have on the price-quality choice and the advertising intensity of the seller. Building upon the above observations, we shall assume that $A_{t}^{\prime}(n, t)>0$ and distinguish between targeted advertising and customer directed advertising.

Proposition 2 [Targeted advertising]

(i) Targeted advertising arises in equilibrium only if there exists $t \in\left(q^{m}, 1\right)$ such that $\pi^{m} r_{t}^{\prime}(n, t)-$ $A_{t}^{\prime}(n, t)=0$. The equilibrium price-quality choice under targeted advertising equals $\left(p^{m}, s^{m}\right)$. (ii) Moreover, under a constant-elasticity advertising technology, targeted advertising is more intense than mass advertising. 
Proof. (i) The profits of the monopolist are given by

$$
\Pi(\cdot)=(p-c(s)) \min \{Q(p, s), t\} r(n, t)-A(n, t) .
$$

From Proposition 1, it follows that, for any $t>Q(p, s)$, the price-quality pair that maximizes seller's profits is $\left(p^{m}, s^{m}\right)$. Differentiation with respect to $t$ yields

$$
\left(p^{m}-c\left(s^{m}\right)\right) q^{m} r_{t}^{\prime}(n, t)-A_{t}^{\prime}(n, t)=0
$$

The monopolist uses targeted advertising to promote sales only if equation (3) has an interior solution; the result follows.

(ii) Let $\widehat{t}$ be the solution to equation (3). Differentiating profits with respect to $n$ yields

$$
\left(p^{m}-c\left(s^{m}\right)\right) q^{m} r_{n}^{\prime}(n, t)-A_{n}^{\prime}(n, t)=0 .
$$

We now show that $d n / d t<0$ for all $t \in(\widehat{t}, 1)$. To obtain $d n / d t$, we differentiate equation (4) totally:

$$
\pi^{m}\left[r_{n t}^{\prime \prime}(n, t) d t+r_{n n}^{\prime \prime}(n, t) d n\right]-A_{n t}^{\prime \prime}(n, t) d t-A_{n n}^{\prime \prime}(n, t) d n=0 .
$$

Isolating $d n / d t$ yields

$$
\frac{d n}{d t}=-\frac{\pi^{m} r_{n t}^{\prime \prime}(n, t)-A_{n t}^{\prime \prime}(n, t)}{\pi^{m} r_{n n}^{\prime \prime}(n, t)-A_{n n}^{\prime \prime}(n, t)}
$$

The denominator of this expression is negative (second order conditions). Thus, the sign of $d n / d t$ is equal to the sign of $\pi^{m} r_{n t}^{\prime \prime}(n, t)-A_{n t}^{\prime \prime}(n, t)$. For a constant-elasticity advertising technology, we have that $r_{t}^{\prime}(n, t)=n^{\alpha} f^{\prime}(t), A_{t}^{\prime}(n, t)=a^{\prime}(t) n, r_{n t}^{\prime \prime}(n, t)=\alpha n^{\alpha-1} f^{\prime}(t), A_{n t}^{\prime \prime}(n, t)=a^{\prime}(t)$. Therefore, $r_{n t}^{\prime \prime}(n, t)=\alpha r_{t}^{\prime}(n, t) / n$, and $A_{n t}^{\prime \prime}(n, t)=A_{t}^{\prime}(n, t) / n$. Thus, the sign of (5) equals the sign of

$$
\frac{1}{n}\left[\pi^{m} \alpha r_{t}^{\prime}(n, t)-A_{t}^{\prime}(n, t)\right]<\frac{1}{n}\left[\pi^{m} r_{t}^{\prime}(n, t)-A_{t}^{\prime}(n, t)\right]<0,
$$

where the last inequality follows from the fact that $t \in(\widehat{t}, 1)$; the result follows.

Seen together, Propositions 1 and 2 show that a targeted advertising strategy leads to the same price-quality choice as a mass advertising strategy, and, further, that this choice equals that under full information. However, this result does not imply that mass and targeted advertising necessarily lead to exactly the same market outcome. The difference between these advertising strategies is the intensity with which the seller promotes sales. Proposition 2,(ii) suggests that, typically, the higher effectiveness embodied in a targeted advertising strategy compared to a mass advertising strategy will lead the firm to acquire a number of ads greater under the former strategy than under 
the latter. Taking into account that from a social perspective a monopolist always undersupplies informative advertising (Shapiro, 1980), it follows that the use of targeted advertising is in fact welfare improving.

We now turn to analyze the case in which the seller promotes sales by using a customer directed advertising strategy. Our first observation is that a monopolist will never choose a target $t$ and a price-quality pair $(p, s)$, such that $Q(p, s)>t$.

Lemma 1 Under customer directed advertising $t=Q(p, s)$.

Proof. By way of contradiction, assume that $Q(p, s)>t>0$. Then, the profits of the monopolist are given by

$$
\Pi(\cdot)=(p-c(s)) \operatorname{tr}(n, t)-A(n, t)
$$

which decrease monotonically with $s$. Therefore, in equilibrium, any $t<Q(p, s)$ should be accompanied by $s=0$. However, $Q(p, 0)=0<t$ for any $t$, which constitutes a contradiction.

Our second result shows that if there are strong economies of targeting, then customer directed advertising arises in equilibrium. Moreover, we note that a customer directed advertising strategy has an important bearing on the market outcome. Let $\left(q^{d}, p^{d}, s^{d}\right)$ denote the equilibrium quantity, price and quality of the seller under customer directed advertising. Then:

Proposition 3 [Customer directed advertising]

(i) If there are strong economies of targeting, customer directed advertising arises in equilibrium.

(ii) Under customer directed advertising the optimal price-quality choice of the monopolist is such that:

(a) $q^{d}<q^{m}$,

(b) $s^{d}<s^{m}$ if and only if $P_{s q}^{\prime \prime}>0$.

(c) If $P_{s q}^{\prime \prime}<0$, then $p^{d}>p^{m}$.

Proof. (i) If conditions (i) and (ii) in Definition 2 above hold, then $(p-c(s)) Q(p, s) r_{t}^{\prime}(n, t)-$ $A_{t}^{\prime}(n, t)<0$. But this implies that the first derivative of the seller's profit function with respect to $t$ is always negative. Consequently, $t=Q(p, s)$.

(ii) It is useful to employ the inverse demand function to write the problem of the monopolist under customer directed advertising as follows:

$$
\operatorname{Max}_{\{q, s, n\}}[P(q, s)-c(s)] q r(n, q)-A(n, q)
$$


The first order conditions of this problem are:

$$
\begin{gathered}
{\left[P(q, s)+P_{q}^{\prime}(q, s) q-c(s)\right] r(n, q)+[P(q, s)-c(s)] q r_{q}^{\prime}(n, q)-A_{q}^{\prime}(n, q)=0} \\
P_{s}^{\prime}(q, s)-c^{\prime}(s)=0 \\
{[P(q, s)-c(s)] q r_{n}^{\prime}(n, q)-A_{n}^{\prime}(n, q)=0}
\end{gathered}
$$

Note first that the optimal quality choice does not depend directly on the number of ads acquired $n$. Let us denote the solution of (8) as $s=s^{d}(q)$. The fact that customer directed advertising occurs in equilibrium implies that $[P(q, s)-c(s)] q r_{q}^{\prime}(n, q)-A_{q}^{\prime}(n, q)<0$. Therefore, a solution to equations (7) and (8) must satisfy $P\left(q, s^{d}(q)\right)+P_{q}^{\prime}\left(q, s^{d}(q)\right) q-c\left(s^{d}(q)\right)>0$. Note that, for a given quantity $q$, the quality choice under perfect information $s^{m}(q) \equiv s^{d}(q)$. Then, it must hold that $P\left(q, s^{d}(q)\right)+P_{q}^{\prime}\left(q, s^{d}(q)\right) q-c\left(s^{d}(q)\right)=P\left(q, s^{m}(q)\right)+P_{q}^{\prime}\left(q, s^{m}(q)\right) q-c\left(s^{m}(q)\right)>0$. Since $P\left(q^{m}, s^{m}\left(q^{m}\right)\right)+P_{q}^{\prime}\left(q^{m}, s^{m}\left(q^{m}\right)\right) q^{m}-c\left(s^{m}\left(q^{m}\right)\right)=0$ and $P(q, s(q))+P_{q}^{\prime}(q, s(q)) q-c(s(q))$ is a decreasing function of $q$ (second order conditions), it follows that $q^{d}<q^{m}$. This proves (a)

(b) From (8) it follows that $s^{d}=s\left(q^{d}\right)$ satisfies $P_{s}^{\prime}\left(q^{d}, s^{d}\right)=c^{\prime}\left(s^{d}\right)$. Similarly $s^{m}=s\left(q^{m}\right)$ is the solution to $P_{s}^{\prime}\left(q^{m}, s^{m}\right)=c^{\prime}\left(s^{m}\right)$. Since $q^{d}<q^{m}, P_{s}^{\prime}\left(q^{d}, s^{m}\right)-c^{\prime}\left(s^{m}\right)>0$ if and only if $P_{s q}^{\prime \prime}<0$. Maximization requires that the second order conditions are satisfied, i.e., $P_{s s}^{\prime \prime}(\cdot)-c^{\prime \prime}(\cdot)<0$. This implies that $P_{s}^{\prime}\left(q^{d}, s\right)-c^{\prime}(s)$ declines with $s$ and, therefore, that there exists $s^{d}>s^{m}$ such that $P_{s}^{\prime}\left(q^{d}, s^{d}\right)-c^{\prime}\left(s^{d}\right)=0$. The other case is proved similarly.

(c) Notice that $d P(q, s(q)) / d q=P_{q}^{\prime}+P_{s}^{\prime} s_{q}^{\prime}$. Since $P_{s q}^{\prime \prime}<0$ implies $s_{q}^{\prime}<0$, the result follows.

We now elaborate on two aspects of this result. The first pertains to the nature of the conditions under which customer directed advertising arises. The second relates to the profound implications that a customer directed advertising strategy has for quantity and quality provision.

Proposition 3 shows that the existence of strong economies of targeting suffices to observe customer directed advertising. We note however that the seller will use this advertising strategy to promote sales under conditions that are weaker than those in Definition 2; in particular, $r_{t}^{\prime}(n, t)<0$ suffices for customer directed advertising to arise in equilibrium (see the proof of this result). Below, we shall present empirical evidence pertaining to the advertising technology of specialized magazines discussed above to suggest that this condition holds.

Second, Proposition 3 shows that if the seller is able to target advertisements to those consumers who are not rationed by the price-quality mechanism, this has an important bearing on the market outcome. In particular, we can see that, under customer directed advertising, the seller brings fewer units to the market, may offer lower quality and may charge higher prices, as compared to a full information setting. We now elaborate on the economic intuition behind these results. 
We note first that under customer directed advertising, any variation in the seller's pricequality choice modifies the size of the targeted segment $t=Q(p, s)$, which in turn has a bearing on advertising costs. This is the fundamental feature of customer directed advertising: it establishes a direct linkage between the size of the potential demand and the cost of the advertising campaign. This in turn gives the firm incentives to deviate from the equilibrium price-quality choice under full information.

Second, a monopolist who employs customer directed advertising puts fewer units in the market; this implies that the typical quantity distortion introduced by a monopolist is greater under customer directed advertising than under full information. For a given level of quality, this translates immediately into a higher price.

Third, we note that the level of quality supplied by the firm is also distorted. Interestingly, the direction of this distortion is sensitive to the nature of product quality. We distinguish quality as an 'intrinsic' attribute to the product from quality as an 'extrinsic' attribute to the product. We say that quality is 'intrinsic' ('extrinsic') when the willingness to pay for an extra unit of quality if higher for those consumers who have higher (lower) valuations for the good, i.e., when $P_{s q}^{\prime \prime}<(>) 0$. Examples in which quality has an 'intrinsic' nature are those in which extra quality means superior technical features, like the speed of operation of a microprocessor, or the capacity of a hard disk, in the market for computers. In such a case, quality is distorted upwards. By contrast, when quality is an 'extrinsic' attribute of the product, like, also in the market for computers, the case of side services such as getting-started tutorials, home installation, then quality is distorted downwards. The economic intuition behind this observation stems from the first order condition (8) above. This equation reveals that the incentives of the seller to invest in quality provision are related to the willingness to pay for an extra unit of quality of the marginal consumer. Since the quantity put in the market under customer directed advertising is lower than the full information optimal quantity, the question is whether the marginal consumer in the first case is willing to pay more or less for quality than the marginal consumer in the second case. When quality is intrinsic, the marginal consumer under customer directed advertising advertising values more quality than that under full information and, consequently, the seller invests in quality upgrading. By contrast, when quality is extrinsic, the opposite holds and the seller downgrades quality.

Finally, to account for price distortions, we note that both the quantitative as well as the qualitative implications of this advertising strategy must be taken into consideration. When the willingness to pay for an extra unit of quality decreases with the quantity put in the market, then the price charged by the monopolist is higher. By contrast, if the willingness to pay for quality increases with the quantity, then the price may increase or decrease. Hence, a customer directed 
advertising strategy may be accompanied with fewer units of lower quality offered at a higher price!

Obviously, the interest of these results depends on the practical relevance of customer directed advertising. To shed light on this point, it is convenient to find empirical evidence about the relationship between the probability with which a consumer sees an advertisement and the target of the advertising campaign. Unfortunately, $r(n, t)$ is not directly observable, and therefore it is difficult to provide evidence about the sign of $r_{t}^{\prime}(n, t)$. A possible way out is, again, to restrict ourselves to the class of advertising technologies with nested specialized magazines. For this class of advertising technologies, as derived above, we have that the sign of $r_{t}^{\prime}(n, t)$ is equal to the sign of $\left(z_{t}^{\prime}(t) t-z(t)\right)$ where $z(t)$ is the readership of magazines of target $t$. Basing on the information we have compiled from the 'Handbook of the Dutch Press and Publicity (2001)' (Tables A.1 and A.2 in the Appendix), we can approximate the value of $z(t)$ by the average readership of the class of magazines corresponding to the target $t$. Again, as a proxy for $t$ to be used in the computation of $r_{t}^{\prime}(n, t)$, we have chosen the largest readership of those magazines of target $t$. Table 2 provides this information.

\begin{tabular}{||l|r|r|r||}
\hline \hline \multicolumn{1}{|c|}{ Magazines } & Av. Readership $z(t)$ & Target $t$ & $\frac{z^{\prime}(t) t}{z(t)}-1$ \\
\hline \hline General Medicine & 12,673 & 21,240 & \\
\hline \hline Cardiology & 2,150 & 2,500 & -0.347 \\
\hline Neurology & 1,542 & 1,875 & -0.301 \\
\hline Buccal Health & 1,850 & 1,850 & -0.442 \\
\hline Logopedia/Phonetics & 4,903 & 4,903 & -0.524 \\
\hline Midwifery & 2,600 & 2,600 & -0.459 \\
\hline Oncology & 2,177 & 3,355 & -0.096 \\
\hline Psychiatry & 2,364 & 3,800 & -0.049 \\
\hline \hline General Computers & 119,976 & 187,499 & \\
\hline \hline Macintosh & 21,000 & 21,000 & -0.472 \\
\hline Atari & 20,000 & 20,000 & -0.403 \\
\hline Games & 51,954 & 74,772 & -0.132 \\
\hline Microsoft & 40,000 & 40,000 & -0.457 \\
\hline WordPerfect/Corel & 25,000 & 25,000 & -0.415 \\
\hline Windows & 40,000 & 40,000 & -0.457 \\
\hline Nintendo64 & 18,000 & 18,000 & -0.398 \\
\hline \hline
\end{tabular}

Table 2. Empirical Evidence on Dutch Magazines: $r_{t}^{\prime}(n, t)$ 
This empirical evidence suggests that $r_{t}^{\prime}(n, t)$ is generally negative, which means that a seller should generally choose customer directed advertising to promote sales. Seen from another point of view, the joint evidence reported in Tables 1 and 2 suggests that the conditions which are necessary for mass advertising as well as targeted advertising to arise in equilibrium do not hold (see equations (2) and (3) above). As a result, it is expected that these advertising strategies will lose practical relevance as advertising technologies evolve over time. Thus, imposing exogenously a mass advertising strategy -as most of the literature has done so far (see the Introduction)- may no longer be a fortunate working assumption in many contexts.

Against this background, a key issue is to determine how the availability of customer directed advertising impacts the degree of market power of the firm. To that end, we take the Lerner index as a measure of market power: $L(q, s)=(P(q, s)-c(s)) / P(q, s)$. We note that $\partial L(\cdot) / \partial p>0$, and $\partial L(\cdot) / \partial s<0$. The signs of these derivatives make this examination non-trivial, since when the firm employs a customer directed advertising strategy, both quality and price may move in the same direction. Let us denote by $L_{m}\left(q^{m}, s^{m}\left(q^{m}\right)\right)$ the Lerner index under full information. We note that $L_{m}(\cdot)$ derives from a simple elasticity rule:

$$
\frac{P\left(q, s^{m}(q)\right)-c\left(s^{m}(q)\right)}{P\left(q, s^{m}(q)\right)}=\frac{1}{E_{p}\left(q, s^{m}(q)\right)},
$$

where $E_{p}(q, s)$ denotes the price elasticity of demand. Let us denote by $L_{d}\left(q^{d}, s^{d}\left(q^{d}\right)\right)$ the Lerner index under customer directed advertising. Substituting (8) in (7), the following relationship obtains:

$$
\left[P\left(q, s^{d}(q)\right)-c\left(s^{d}(q)\right)\right]\left[1+\frac{q r_{q}^{\prime}(n, q)}{r(n, q)}\right]-\frac{P\left(q, s^{d}(q)\right)}{E_{p}\left(q, s^{d}(q)\right)}=\frac{A_{q}^{\prime}(n, q)}{r(n, q)}
$$

Taking into consideration that $s^{m}(q) \equiv s^{d}(q)$, some algebra yields that $L_{d}\left(q^{d}, s^{d}\left(q^{d}\right)\right)=L_{d}\left(q^{d}, s^{m}\left(q^{d}\right)\right)$, the latter being determined by the following equation:

$$
\frac{P\left(q, s^{m}(q)\right)-c\left(s^{m}(q)\right)}{P\left(q, s^{m}(q)\right)}=\left[\frac{1}{E_{p}\left(q, s^{m}(q)\right)}+\frac{A_{q}^{\prime}(n, q)}{P\left(q, s^{m}(q)\right) r(n, q)}\right] \frac{1}{\left[1+\frac{q r_{q}^{\prime}(n, q)}{r(n, q)}\right]} .
$$

The comparison between (10) and (11) reveals that the change in seller's degree of market power when he uses customer directed advertising rather than mass advertising depends on the signs of $A_{t}^{\prime}(n, t), r_{t}^{\prime}(n, t)$, and $d E_{p} / d q$. Since $A_{t}^{\prime}(n, t)>0$, and since it is reasonable to assume that $r_{t}^{\prime}(n, t)<0$ under customer directed advertising - which is corroborated by the empirical evidence given above-, for a given $n$, we have that, $A_{q}^{\prime}(n, q) /\left(P\left(q, s^{m}(q)\right) r(n, q)\right)>0$, and $q r_{q}^{\prime}(n, q) / r(n, q)<$ 0 . Consequently, noting that $q^{d}<q^{m}$, we have the following result:

Proposition 4 Assume that $A_{t}^{\prime}(n, t)>0$ and $r_{t}^{\prime}(n, t)<0$. Then, $L_{d}(\cdot)>L_{m}(\cdot)$ if $d E_{p} / d q \geq 0$. 
This Proposition gives a sufficient condition under which the market allocation chosen by a monopolist who uses customer directed advertising to promote sales gives greater market power to the seller. This result, however, does not necessarily imply that a customer directed advertising strategy is welfare reducing. The reason is that, under customer directed advertising, every ad returns a sale and, thus, this advertising strategy is more effective than others. This remark calls for an examination of how the transition from mass to customer directed advertising can affect welfare. In general, from the society point of view, we must trade-off possible increases in the deadweight-loss against gains in advertising efficiency. We undertake this task in the next Section.

\section{Welfare}

We address three issues in this Section. The first issue we examine pertains to the conditions under which a social planner uses customer directed advertising to promote sales. The second compares the social incentives for quantity and quality provision under mass advertising and under customer directed advertising. Finally, we examine the question left open above about whether the private adoption of customer directed advertising has a negative impact on the level of social welfare.

As a welfare measure, we take the conventional expression of gross consumer surplus minus production and advertising costs:

$$
W(q, s, n, t)=\int_{0}^{q} P(\mu, s) d \mu r(n, t)-c(s) r(n, t)-A(n, t) .
$$

The next Proposition shows that the social incentives to choose a customer directed advertising strategy are somewhat aligned with the private incentives. In particular, if there are strong economies of targeting, the social planner finds it optimal to use a customer directed advertising strategy. This is consistent with the seller's choice. The Proposition also reveals that the social incentives for quantity and quality provision may be misaligned with the private ones. Let $\left(q_{m}^{*}, s_{m}^{*}\right)$ and $\left(q_{d}^{*}, s_{d}^{*}\right)$ be the optimal quantity and quality put in the market by a social planner who promote sales through mass and customer directed advertising, respectively.

Proposition 5 (i) If there are strong economies of targeting, the planner promotes sales by customer directed advertising. (ii) Moreover, under customer directed advertising, the socially optimal quantity-quality choice is such that $q_{d}^{*}<q_{m}^{*}$, and $s_{d}^{*}<s_{m}^{*}$.

Proof. (i) The planner uses customer directed advertising if and only if

$$
\int_{0}^{q}\left[(P(\mu, s)-c(s)] d \mu r_{t}^{\prime}(n, t)-A_{t}^{\prime}(n, t)<0,\right.
$$


which holds, given Definition 2.

ii) Under mass advertising, the first order conditions with respect to $q$ and $s$ are

$$
\begin{gathered}
{[(P(q, s)-c(s)] r(n, 1)=0} \\
\int_{0}^{q} P_{s}^{\prime}(\mu, s) d \mu-c^{\prime}(s)=0,
\end{gathered}
$$

respectively. Under customer directed advertising, $t=Q(p, s)$ and the first order conditions with respect to $q$ and $s$ are, in this case,

$$
\begin{gathered}
{\left[(P(q, s)-c(s)] r(n, q)+\int_{0}^{q}\left[(P(\mu, s)-c(s)] d \mu r_{q}^{\prime}(n, q)-A_{q}^{\prime}(n, q)=0\right.\right.} \\
\int_{0}^{q} P_{s}^{\prime}(\mu, s) d \mu-c^{\prime}(s)=0,
\end{gathered}
$$

respectively. If $s_{m}^{*}(q)$ and $s_{d}^{*}(q)$ are solutions to (14) and (16), respectively, then it follows that $s_{m}^{*}(q) \equiv s_{d}^{*}(q)$. Thus, substituting (14) into (13) yields $P\left(q_{m}^{*}, s_{m}^{*}\left(q_{m}^{*}\right)\right)=c\left(s_{m}^{*}\left(q_{m}^{*}\right)\right)$ or, equivalently, $P\left(q_{m}^{*}, s_{d}^{*}\left(q_{m}^{*}\right)-c\left(s_{d}^{*}\left(q_{m}^{*}\right)\right)=0\right.$. Moreover, since (12) holds under customer directed advertising, equation (15) implies $P\left(q_{d}^{*}, s_{d}^{*}\left(q_{d}^{*}\right)\right)-c\left(s_{d}^{*}\left(q_{d}^{*}\right)\right)>0$. Since $P(q, s)-c(s)$ is a decreasing function of $q$ (second order conditions), it follows that $q_{d}^{*}<q_{m}^{*}$. Finally, applying the implicit function theorem to (14), we obtain the nature of the relationship between quality and quantity:

$$
\frac{d s}{d q}=-\frac{P_{s}^{\prime}(q, s)}{\int_{0}^{q} P_{s s}^{\prime \prime}(\mu, s) d \mu-c^{\prime \prime}(s)}>0
$$

where the inequality follows from the conditions above. Since $q_{d}^{*}<q_{m}^{*}$, it follows that $s_{d}^{*}<s_{m}^{*}$.

This result shows that when the advertising technology presents strong economies of targeting, the social planner restricts the quantity and downgrades the quality of the product. The first effect is in line with the seller's decision; by contrast, while the seller may upgrade quality in some cases, the social planner always reduces the supply of quality (see Proposition 3). This misalignment between the private and the social incentives to alter quality arises because while the seller only cares about the willingness to pay for an extra unit of quality of the marginal consumer (see equation (8)), the social planner is concerned with the aggregate willingness to pay for an extra unit of quality (see (14)). The former may increase or decrease according to whether quality is intrinsic or extrinsic, respectively, while the latter always decreases.

These remarks lead us to question what is the nature of the impact that the private adoption of customer directed advertising has on social welfare. Of course, this examination is in the spirit 
of a second best analysis. We have been unable to offer a general characterization of the conditions under which the private adoption of customer directed advertising reduces welfare. To gain further insight in this issue, we have chosen to solve our model for a particular family of demand and cost functions. This family encompasses models often employed in the literature and captures the 'intrinsic' and 'extrinsic' nature of product quality. We now present the details of this specification.

\section{Demand function:}

We assume that market demand stems from a unitary mass of consumers characterized by a taste parameter $\theta$ uniformly distributed in the unit interval. A consumer's utility is $U=\theta+f(s)-$ $\theta g(s)-p$, when he buys the good of quality $s$ at price $p$, with $f(s) \geq 0, f(s)-\theta g(s) \geq 0$, and $f^{\prime}(s)-\theta g^{\prime}(s)>0$. No consumption gives zero utility. The economic interpretation of this utility function is the following: (i) Since $\theta>0$, consumers enjoy the good per se; (ii) $f(s) \geq 0$ indicates that consumers may attach value to quality per se, independently of the taste parameter; finally, (iii) $f(s)-\theta g(s) \geq 0$ together with $f^{\prime}(s)-\theta g^{\prime}(s)>0$ imply that consumers always prefer higher qualities. $^{8}$ We note that this manner of modelling vertical product differentiation encompasses a number of utility functions frequently found in the literature. ${ }^{9}$ Standard derivations yield a demand function $Q(p, s)=1-(p-f(s)) /(1-g(s))$. We now consider that $f(s)=s-1 / s^{k-1}$ and $g(s)=1-1 / s^{k-1}$, which satisfy the above conditions for all $\theta \in[0,1]$ when $k \geq 0$ and $s>1$. It obtains that $Q(p, s)=s^{k}(1-p / s)$. We note that $k<1$ refers to a situation where quality attributes are 'intrinsic', i.e., $P_{s q}^{\prime \prime}<0$; by contrast, $k>1$ gathers the case of 'extrinsic' quality attributes, i.e., $P_{s q}^{\prime \prime}>0$. Finally, the case $k=1$ will be regarded as a 'neutral' case.

\section{Advertising and production cost functions:}

We consider the advertising technology $\{A(n, t), r(n, t)\}=\left\{n a(t), n^{\alpha} f(t)\right\}$. As pointed out above, this advertising technology encompasses the family of polynomial advertising cost functions with constant elasticity. We further assume that $f(t)=t^{-\alpha}$ and $\alpha=1 / 2$. Furthermore, we note that, in line with the empirical evidence provided in Table 3, $a$ is rather insensitive to $t$; thus, for the sake of simplicity, we assume $a(t)=a(1)=a$. Finally, we employ a marginal cost specification quadratic in quality, $c(s)=b s^{2} / 2$.

With these market conditions at hand, one can solve the problems (1) and (6) outlined above. These give us the equilibrium market allocations and advertising intensities under mass and cus-

\footnotetext{
${ }^{8}$ We note that this specification allows for the valuation of quality to be positively or negatively related to the taste parameter, i.e., we do not place any restriction on the sign of $g(s)$.

${ }^{9}$ In particular, setting $f(s)=0$ and $g(s)=1-s$ yields $U=\theta s-p$ (Mussa and Rosen, 1978). Moreover, setting $f(s)=g(s)=s$ leads to $U=\theta+(1-\theta) s-p($ Tirole, 1988, p. 104).
} 
tomer directed advertising, respectively. We obtain:

$$
\begin{aligned}
& p^{m}=\frac{2(1+k)(2+k)}{b(3+k)^{2}}, s^{m}=\frac{2(1+k)}{b(3+k)}, r^{m}=\frac{2^{k}(1+k)^{1+k}}{a b^{1+k}(3+k)^{3+k}}, n^{m}=\frac{4^{k}(1+k)^{2+2 k}}{a^{2} b^{2+2 k}(3+k)^{6+2 k}} \\
& p^{d}=\frac{2\left(k^{2}+6 k+8\right)}{b(5+k)^{2}}, s^{d}=\frac{2(2+k)}{b(5+k)}, r^{d}=\frac{2(2+k)}{a b(5+k)^{2}}, \quad n^{d}=\frac{2^{2+k}(2+k)^{2+k}}{a^{2} b^{2+k}(5+k)^{5+k}}
\end{aligned}
$$

On the basis of these results, we can compute the impact that moving from a mass advertising strategy to a customer directed advertising strategy has on social welfare. Table 3 displays the percent changes in price, quality and degree of market power (Lerner index) for various values of the parameter $k$. These values have been chosen so that they generate an advertising cost-to-sales ratio ranging from $8 \%$ to $25 \%$. This is consistent with the stylized fact that when a firm launches a new product, it usually incurs an advertising cost that represents an average of about $20 \%$ of sales (Kotler and Armstrong, 1998). The table also reports the set of values $\Psi=[\underline{b}, \bar{b}]$ for which the above problems have interior solutions that satisfy $q<1$ and $s>1$. Finally, the table contains the subset of values of $b$ for which consumer surplus and social welfare decrease (sets $\Theta$ and $\Omega$, respectively).

\begin{tabular}{||c||c||c||c||c||c||c||}
\hline \hline & $\mathrm{k}=0$ & $\mathrm{k}=0.5$ & $\mathrm{k}=1$ & $\mathrm{k}=2$ & $\mathrm{k}=3$ & $\mathrm{k}=4$ \\
\hline \hline$\frac{p_{d}-p_{m}}{p_{m}}$ & $+44 \%$ & $+21 \%$ & $+11 \%$ & $+2 \%$ & $-1.5 \%$ & $-3.2 \%$ \\
\hline$\frac{s_{d}-s_{m}}{s_{m}}$ & $+20 \%$ & $+6 \%$ & $0 \%$ & $-4.8 \%$ & $-6.2 \%$ & $-6.7 \%$ \\
\hline$L_{m}$ & $+50 \%$ & $+40 \%$ & $+33 \%$ & $+25 \%$ & $+20 \%$ & $+16 \%$ \\
\hline$\frac{L_{d}-L_{m}}{L_{m}}$ & $0 \%$ & $+11 \%$ & $+20 \%$ & $+33 \%$ & $+44 \%$ & $+50 \%$ \\
\hline$\Psi$ & {$[0 ; 0.66]$} & {$[0.07 ; 0.85]$} & {$[0.25 ; 1]$} & {$[0.53 ; 1.14]$} & {$[0.73 ; 1.25]$} & {$[0.87 ; 1.39]$} \\
\hline$\Theta$ & $\emptyset$ & {$[0.07 ; 0.19]$} & {$[0.25 ; 0.42]$} & {$[0.53 ; 0.69]$} & {$[0.73 ; 0.86]$} & {$[0.87 ; 0.98]$} \\
\hline$\Omega$ & $\emptyset$ & {$[0.07 ; 0.08]$} & {$[0.25 ; 0.28]$} & {$[0.53 ; 0.56]$} & {$[0.73 ; 0.75]$} & {$[0.87 ; 0.89]$} \\
\hline \hline
\end{tabular}

Table 3. Simulation Results

Table 3 shows a number of issues. The first is that the welfare implications of customer directed advertising are sensitive to the quality attributes of the product. In particular, on average, the size of the sets $\Omega$ and $\Theta$ relative to the set $\Psi$ is greater for $k>1$ than for $k<1$. This implies that the set of parameters for which consumer surplus and welfare decrease when quality is an extrinsic attribute to the product is larger than when quality has an intrinsic nature. The second issue we see is that the size of $\Omega$ relative to $\Psi$ is generally quite small. This suggests that, even though the possibility that customer directed advertising leads to a welfare decrease cannot be excluded in this model, the likelihood of occurrence of this event is not large. Finally, additional 
computations yield that, on average, the maximum potential loss for consumers is $33 \%$, whereas the maximum potential social welfare loss is $7.8 \%$. In summary, the analysis of Table 3 suggests that the transition from mass to customer directed advertising is likely to be welfare improving, but may well decrease consumer surplus. We now elaborate on the intuition behind these insights. We distinguish the case of intrinsic, neutral and extrinsic quality attributes to gain in exposition clarity.

Case 1: Intrinsic Quality $(0 \leq k<1)$.

As compared to the use of mass advertising, a customer directed advertising strategy leads to a reduction in the number of units of output that the firm puts in the market. This quantitative-effect has two major implications associated. First, since quality attributes are intrinsic in the case under consideration, a quantity cut implies that the firm targets consumers with a higher willingness to pay for quality. This leads the seller to increase the supply of quality. This quality-effect increases the marginal cost of quality provision $c(s)$, which tends to reduce the firm's degree of market power. Secondly, the quantity-effect has a bearing on the market price. This is given by

$$
\frac{d P}{d q}=\frac{\partial P}{\partial q}+\frac{\partial P}{\partial s} \frac{d s^{d}}{d q}
$$

Since quality is intrinsic, both terms in this equation work in the same direction and, therefore, there is a price-effect which tends to increase the firm's degree of market power, $d P / d q<0$. The case $k=0$ (Mussa and Rosen, 1978) is special, in the sense that the price-effect entirely offsets the quality-effect; this yields the remark that the use of customer directed advertising need not affect the firm's degree of market power. Since market power remains unaltered in such a case, the higher advertising cost efficiency associated to a customer directed advertising strategy implies that this advertising means is beneficial for consumers and for society as a whole. By contrast, if $0<k<1$, the price-effect dominates and thus the use of customer directed advertising generates a trade-off between a higher advertising efficiency and a greater monopoly power, which might lead to a welfare loss. For example, if $k=0.5$, consumer surplus decreases when $b<0.19$, whereas welfare decreases when $b<0.08$ (Table 3 ).

Case 2: Neutral Quality $(k=1)$

In this case, there is no quality-effect and thus the price effect is unambiguously negative. As a result, the use of customer directed advertising always increases the degree of market power, which increases the potential for a welfare loss.

Case 3: Extrinsic Quality $(k>1)$ 
In this situation the quantity effect leads the firm to target consumers with a lower valuation of quality, which in turn drives the monopolist to reduce the supply of quality. Thus, the quality-effect is positive; this tends to further increase the level of market power. Moreover, the fact that the second term in the RHS of equation (17) above is positive, implies that the market price might fall, and so the price-effect could reduce the level of market power. In our example, the quality-effect is always stronger than the price-effect and, therefore, the use of customer directed advertising further increases the firm's degree of market power.

\section{Conclusions}

We have studied an economy where a single seller launches a new product of observable quality. Central to our analysis is the fact that consumers are, in principle, unaware of the existence and the characteristics of the product. This implies that the seller would face no positive demand unless he invested in an advertising campaign to promote sales of his product. We have identified three possible advertising strategies at the disposal of the seller: mass advertising, targeted advertising and customer directed advertising. The feature that distinguishes these advertising strategies is the target of the advertising campaign, that is, the set of consumers to whom the seller distributes ads. We have studied the conditions under which different advertising strategies arise in equilibrium. In addition, we have explored the implications that distinct advertising strategies have on the pricequality choice of the monopolist. Finally, we have examined the welfare implications associated to the adoption of a customer directed advertising strategy.

We have found that the choice of advertising strategy of the seller is intimately related to the properties of the advertising technology at his disposal. When the advertising technology exhibits strong economies of targeting, then the monopolist promotes sales through customer directed advertising. This is a strategy under which no consumer rationed by the price-quality mechanism receives advertisements. In such a case, we have shown that, compared to the market allocation under full information, the seller puts fewer units in the market, and distorts the quality and the price in a manner that is sensitive to the quality attributes to the product. By contrast, a mass advertising strategy as well as a targeted advertising strategy have no impact on the market outcome. We have also gathered empirical evidence supporting the view that the conditions under which customer directed advertising arises in equilibrium seem to hold in real-world markets. The same evidence suggests that mass advertising and targeted advertising may be rather exceptional phenomena in current markets.

We have also compared the social and the private incentives to use CDA advertising and the 
incentives for quantity and quality provision. We have found that a social planner has incentives

to use customer directed advertising somewhat in line with those of the seller. However, the social incentives for quantity and quality provision may differ from those of the monopolist. This potential misalignment of incentives may lead to a welfare loss when the seller uses customer directed advertising rather than mass advertising. We have seen that this potential welfare loss is less likely when quality is an intrinsic attribute of the product. Finally, when there are welfare gains, the firm typically captures a larger fraction than the consumers.

The most fascinating research extension of our model consists of analyzing advertising directed to the customers in an oligopoly setting. In a homogeneous product market, Roy (2000) has analyzed this issue in a two-stage model where firms first advertise and then set their prices. In his model, the advertising technology has the nature of direct-marketing, which differs from ours since distinct firms are able to target ads to disjunct sets of consumers in his paper; moreover, advertising has a long run nature and investments in advertising enable firms to strategically segment the market. However, in a large number of markets advertising has a short run nature instead and such segmentation cannot arise in equilibrium. We expect the analysis of oligopolistic advertising with the specification of our paper to lead to very different results. First, we believe the conditions under which customer directed advertising arises in equilibrium to be weaker under oligopoly than under monopoly. To see this, consider for example a duopoly model of vertical differentiation $a ́$ la Cremer and Thisse (1994). In this model, firms put in the market distinct qualities in an attempt to reduce price competition. It is easy to see that, for any given pair of qualities, under a customer directed advertising strategy, low-quality consumers would only be aware of the product offering of the low-quality firm. This strategic effect weakens competition between the firms and thus increases the incentives of the high-quality firm to use a targeting advertising strategy. Moreover, this may have a bearing on quality provision. Thus, if customer directed advertising arises in equilibrium, the market allocation will probably differ substantially from that under full information, and thus a welfare analysis is called for to be able to evaluate the social welfare implications of targeting technologies in oligopoly. This is work that we are pursuing in a separate paper.

\section{References}

[1] Bagwell, K. (1988), “Advertising and Limit Pricing," Rand Journal of Economics 19-1, 59-71.

[2] Bagwell, K. (2001), The Economics of Advertising, mimeo.

[3] Bagwell, K. and G. Ramey (1990), "Advertising and Pricing to Deter or Accommodate Entry when Demand is Unknown," International Journal of Industrial Economics 8-1, 93-113. 
[4] Bagwell, K. and G. Ramey (1994a), "Advertising and Coordination," Review of Economics Studies 61, 153-172.

[5] Bagwell, K. and G. Ramey (1994b), "Coordination Economies, Advertising and Search Behaviour in Retail Markets," American Economic Review 84-3, 498-517.

[6] Bester, H., 1995, "Random Advertising and Monopolistic Price Dispersion", Journal of Economics and Management Science, 3, 545-559.

[7] Bester, H. and E. Petrakis, 1995, "Price Competition and Advertising in Oligopoly", European Economic Review, 39, 1075-1088.

[8] Bester, H. and E. Petrakis, 1996, "Coupons and Oligopolistic Price Discrimination", International Journal of Industrial Organization, 14, 227-42.

[9] Bloch, F. and D. Manceau (1999), "Persuasive Advertising in Hotelling's Model of Product Differentiation," International Journal of Industrial Organization 17-4, 557-574.

[10] Butters, G. (1977), "Equilibrium Distributions of Sales and Advertising Prices", Review of Economic Studies, 44, 465-491.

[11] Caminal, R. (1996), "Price Advertising and Coupons in a Monopoly Model", Journal of Industrial Economics, 44, 33-52.

[12] Cremer, H. and J.-F. Thisse (1994), "Commodity Taxation in a Differentiated Oligopoly", International Economic Review 35, 613-633.

[13] Dixit, A. and V. Norman (1978), "Advertising and Welfare," Bell Journal of Economics 9-1, $1-17$.

[14] Esteban, L. Gil, A. and J. M. Hernández (2001), "Informative Advertising and Optimal Targeting in a Monopoly," Journal of Industrial Economics 49, 161-180.

[15] Grossman G. and C. Shapiro (1984), "Informative Advertising with Differentiated Products," Review of Economic Studies 51, 63-82.

[16] Guía de los Medios de Comunicación de España (1999), número 136, América Ibérica, Madrid.

[17] Handboek van de Nederlandse Pers en Publiciteit (2001), Nijgh Periodieken B. V., Schiedam, The Netherlands. 
[18] Heighton, E. J., and D. R. Cunningham (1984), Advertising in the Broadcast and Cable Media. Wadsworth Publishing Company. Belmont, California.

[19] Hernández-García, J. M. (1997), "Informative Advertising, Imperfect Targeting and Welfare," Economics Letters 55, 131-137.

[20] Kaldor, N. (1950), "The Economic Aspects of Advertising," Review of Economic Studies 18, $1-27$.

[21] Kotler, P. and G. Armstrong (1998), Marketing-An Introduction, Englewood Cliffs: Prentice Hall.

[22] Moraga-González, J. L. (2000), "Quality Uncertainty and Informative Advertising," International Journal of Industrial Organization 18, 615-640.

[23] Moraga-González, J. L. and E. Petrakis (1999), "Coupon Advertising under Imperfect Price Information," Journal of Economics and Management Strategy 8-4, 523-544.

[24] Mussa, M. and S. Rosen (1978), "Monopoly and Product Quality," Journal of Economic Theory 18, 301-317.

[25] Robert, J. and D. O. Stahl (1993), "Informative Price Advertising in a Sequential Search Model," Econometrica 61-3, 657-686.

[26] Roy, S. (2000), "Strategic Segmentation of a Market," International Journal of Industrial Organization 18-8, 1279-1290.

[27] Shapiro, C. (1980), "Advertising and Welfare: Comment," Bell Journal of Economics 11-2, 749-752.

[28] Stahl, D. O. (1994), "Oligopolistic Pricing and Advertising," Journal of Economic Theory 64, 162-177.

[29] Stegeman, M. (1991), "Advertising in Competitive Markets", American Economic Review 81, 210-223.

[30] Tirole, J. (1988), The Theory of Industrial Organization (Cambridge, MA: MIT Press). 


\section{Appendix}

\begin{tabular}{||l|l|l|r||}
\hline \hline Name & Description & Readership & Ad price \\
\hline \hline Medisch Vandaag & General & 21,240 & 3,601 \\
\hline Medisch Nieuws & General & 7,430 & 2,666 \\
\hline Patient Care & General & 11,000 & 2,649 \\
\hline Geneeskundig Adresboek Nederland & General & 11,024 & 3,487 \\
\hline Eur. J. of Cardio-Thoracic Surgery & Cardiology & 1,800 & 2,929 \\
\hline de Toraxcentre Journal & Cardiology & 2,500 & 2,269 \\
\hline Nederlands Tijdschrift voor Neurologie & Neurology & 1,750 & 2,269 \\
\hline de Neuroloog & Neurology & 1,000 & 2,224 \\
\hline NeuroPraxis & Neurology & 1,875 & 1,484 \\
\hline Nederlands Tijdschrift v. Mondhygiene & Buccal Health & 1,850 & 2,217 \\
\hline Logopedie en Fonietrie & Logopedia/Phonetics & 4,903 & 1,840 \\
\hline Tijdschrift voor Verloskundigen & Midwifery & 2,600 & 440 \\
\hline Tijdschrift voor Kanker & Oncology & 3,355 & 2,085 \\
\hline Medische Oncologie & Oncology & 1,000 & 2,518 \\
\hline Acta Neuropsychiatrica & Psychiatry & 1,370 & 2,060 \\
\hline de Psychiater & Psychiatry & 2,250 & 2,224 \\
\hline Tijdschrift voor Psychiatrie & Psychiatry & 3,800 & 1,443 \\
\hline Vademecum Psychiatrie & Psychiatry & 2,037 & 3,176 \\
\hline \hline
\end{tabular}

Table A.1: Evidence on Dutch medicine magazines. 


\begin{tabular}{||l|l|r|r||}
\hline \hline Name & Description & Readership & Ad price \\
\hline \hline Computer Totaal! & General & 187,499 & 11,305 \\
\hline Computer Idee & General & 156,708 & 10,030 \\
\hline Computer Thuis en Bedrijf & General & 84,700 & 6,480 \\
\hline PC Consument & General & 51,000 & 4,600 \\
\hline MacFan & Macintosh & 21,000 & 3,600 \\
\hline Atari ST Nieuws & Atari & 20,000 & 2,500 \\
\hline PC Gamer & Games & 40,000 & 5,700 \\
\hline Games + & Games & 70,000 & 2,750 \\
\hline Hoog Speel & Games & 25,000 & 4,950 \\
\hline Power Unlimited & Games & 74,772 & 10,452 \\
\hline PC Zone Benelux & Games & 50,000 & 8,000 \\
\hline Microsoft Office Magazine & Microsoft & 40,000 & 5,445 \\
\hline WordPerfect Magazine & Word Perfect/Corel & 25,000 & 4,300 \\
\hline Windows Magazine & Windows & 40,000 & 5,350 \\
\hline Nmagazine & Nintendo64console & 18,000 & 4,250 \\
\hline \hline
\end{tabular}

Table A.2: Evidence on Dutch computer magazines. 